\title{
Sistem Operasi Komputer
}

\author{
Erwan suganda Putra \\ 195120045 \\ Fakultas Komputer \\ erwansuganda.student@umitra.ac.id
}

\begin{abstract}
Sistem operasi merupakan sebuah penghubung antara pengguna dari komputer dengan perangkat keras komputer. Sebelum ada sistem operasi, orang hanya mengunakan komputer dengan menggunakan sinyal analog dan sinyal digital. Seiring dengan berkembangnya pengetahuan dan teknologi, pada saat ini terdapat berbagai sistem operasi dengan keunggulan masing-masing. Untuk lebih memahami sistem operasi maka sebaiknya perlu diketahui terlebih dahulu beberapa konsep dasar mengenai sistem operasi itu sendiri.
\end{abstract}

Tujuan Dari Pembuatan Artikel Ini yaitu :

1.Untuk memenuhi tugas individu mata kuliah Sistem Operasi

2.Memahami komponen pada sistem operasi, manajemen yang diatur sistem operasi dan layanan pada sistem operasi.

3.Memahami komponen pada sistem operasi, manajemen yang diatur system operasi dan layanan pada sistem operasi

4.Mengetahui beberapa struktur system operasi. 
* Fungsi Sistem Operasi

Sistem operasi mempunyai peran penting di dalam suatu sistem komputer. Berikut beberapa fungsi sistem operasi,

1. Memberikan tampilan utama komputer (user interface).

2. Menjalankan beberapa aplikasi dalam waktu yang sama (multitasking).

3. Membagi memory komputer ke aplikasi-aplikasi yang sedang berjalan.

4. Menangani input dan output dari hardware yang tersambung pada sistem komputer.

5. Mengirim pesan ke aplikasi terkait kinerja sistem, sehingga dapat diterima oleh pengguna sesuai dengan tujuan aplikasi.

6. Membuat catatan dari aplikasi yang dijalankan (log).

7. Melakukan manajemen partisi dan file.

8. Melakukan instruksi secara paralel ke prosesor untuk mengoptimalkan kinerja sistem komputer.

9. Manajemen akun pengguna sistem komputer (user account).

10. Menghubungkan BIOS dengan driver dari suatu perangkat keras sehingga perangkat keras bisa dioperasikan. 


\section{A. PENDAhuluan}

Materikuliah section 01 membahas tentang Sistem operasi mempunyai tiga sasaran utama yaitu kenyamanan membuat penggunaan komputer menjadi lebih nyaman, efisien penggunaan sumber-daya sistem komputer secara efisien, serta mampu berevolusi sistem operasi harus dibangun sehingga memungkinkan dan memudahkan pengembangan, pengujian serta pengajuan sistem-sistem yang baru

\section{B. PEMBAHASAN / STUDI KASUS}

\section{$\checkmark$ Pengertian sistem operasi}

Pengertian sistem operasi secara umum ialah pengelola seluruh sumber-daya yang terdapat pada sistem komputer dan menyediakan sekumpulan layanan (system calls) ke pemakai sehingga memudahkan dan menyamankan penggunaan serta pemanfaatan sumber-daya sistem komputer

\section{$\checkmark$ Komponen Sistem Operasi}

Sistem operasi terdiri dari beberapa komponen, antara lain manajemen proses, manajemen memori utama, manajemen file, manajemen sistem I/O, manajemen penyimpan sekunder, system jaringan, system proteksi dan system .

\section{a.Manajemen Proses}

Proses adalah program yang sedang dieksekusi. Sebuah proses memerlukan sumber daya (resource) tertentu seperti waktu CPU, memori, file dan perangkat I/O untuk menyelesaikan tugasnya.

Untuk mengatur proses yang ada, sistem operasi bertanggung jawab pada aktrifitasaktifitas yang berhubungan denagn manajemen proses berikut :

a.Pembuatan dan penghapusan proses yang dibuat oleh user atau sistem.

b.Menghentikan proses sementara dan melanjutkan proses. 


\section{$\checkmark$ Layanan Sistem Operasi}

Sistem operasi menyediakan layanan untuk programmer sehingga dapat melakukan pemrograman dengan mudah.

\section{a.Eksekusi Program}

Sistem harus dapat memanggil program ke memori dan menjalankannya. Program tersebut harus dapat mengakhiri eksekusinya dalam bentuk normal atau abnormal (indikasi error).

b.Operasi-operasi I/O

Pada saat running program kemungkinan dibutuhkan I/O, mungkin berupa file atau peralatan I/O. Agar efisien dan aman, maka user tidak boleh mengontrol I/O secara langsung, pengontrolan dilakukan oleh sistem operasi.

c.Manipulasi sistem file

Kapabilitas program untuk membaca, menulis, membuat dan menghapus file.

\section{$\checkmark$ SISTEM CALL}

System call menyediakan antar muka antara program yang sedang berjalan dengan sistem operasi. System call biasanya tersedia dalam bentuk instruksi bahasa assembly.

Terdapat 3 (tiga) metode yang umum digunakan untuk melewatkan parameter antara program yang sedang berjalan dengan sistem opeasi yaitu :

- Melewatkan parameter melalui

Register.

- Menyimpan parameter pada

tabel yang disimpan di memori dan alamat tabel tersebut dilewatkan sebagai parameter di register seperti Gambar 2-1.

- Push

(menyimpan) parameter ke stack oleh program dan pop (mengambil) isi stack yang dilakukan oleh system operasi. 


\section{Fakultas Komputer Erwan Suganda Putra}

Section 02

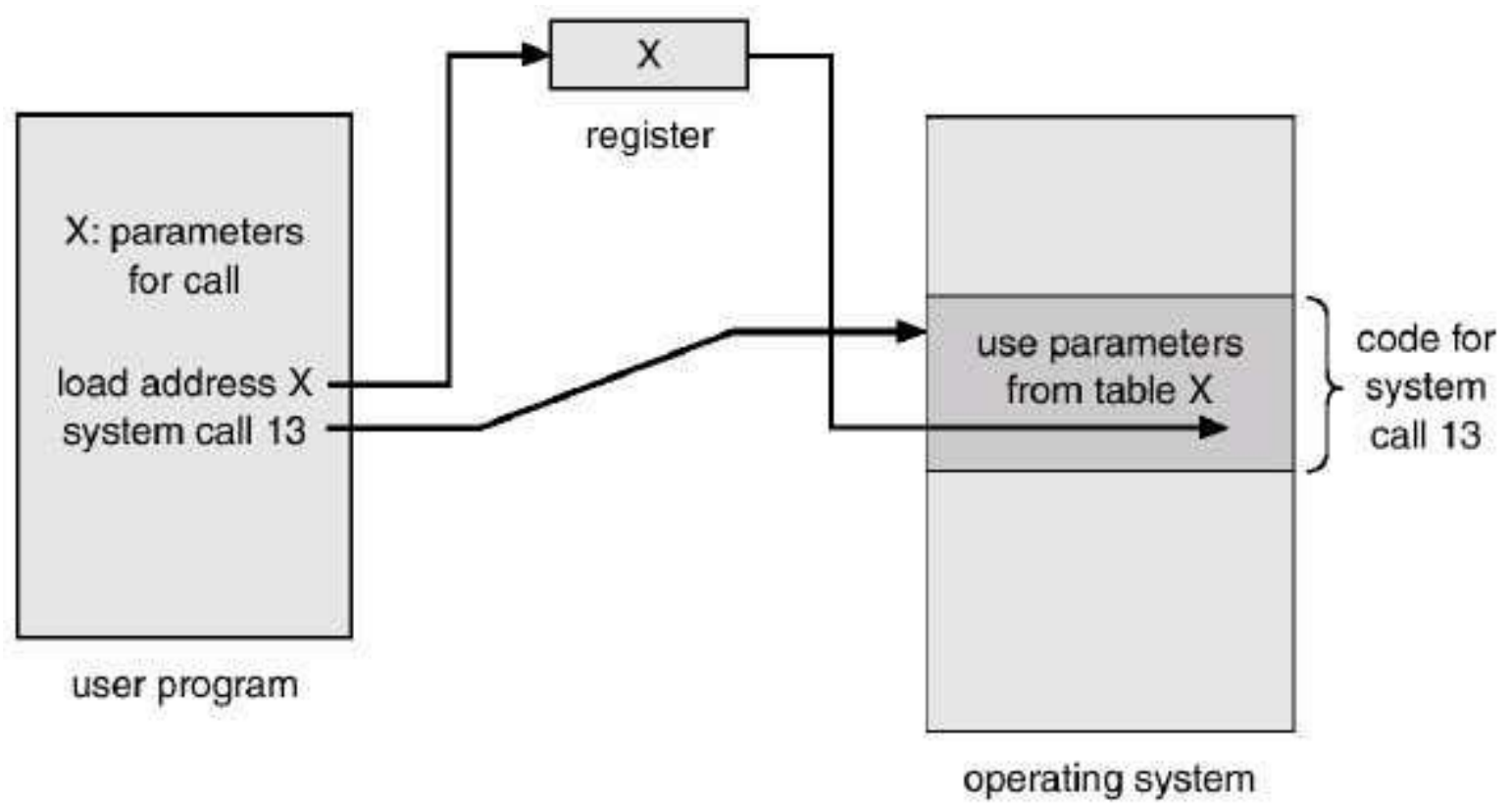

Pada dasarnya System call dapat dikelompokkan dalam 5 kategori seperti yang dijelaskan pada sub bab di bawah ini.

a.KontrolProses

Hal-hal yang dilakukan:

- Mengakhiri (end ) dan membatalkan (abort );

- Mengambil (load ) dan eksekusi (execute); 


\section{ID SECURITY}

$$
\text { QWTD44112377-ASP-524414475 }
$$

\section{KESIMPULAN}

Kesimpulan dari materiini adalah Sistem operasi adalah software yang berfungsi untuk mengaktifkan seluruh perangkat yang terpasang pada komputer sehingga masingmasingnya dapat saling berkomunikasi. Secara umum, Sistem Operasi adalah software pada lapisan pertama yang ditaruh pada memori komputer pada saat komputer dinyalakan.

\section{E. DISKUSI}

Saya bersama teman saya bernama redo mendiskusikan tentang pengertian system operasi ini dengan sangat baik hasil diskusi dari materi ini adalah untuk mengorganisasikan data sedemikian rupa sehingga implemental ( penerapan ) atau pemeliharaan logika program menjadi lebih terstruktur.Dalam istilah ilmu computer. 


\section{F. REFERENCE}

[1] O. M. Febriani and A. S. Putra, "Sistem Informasi Monitoring Inventori Barang Pada Balai Riset Standardisasi Industri Bandar Lampung," J. Inform., vol. 13, no. 1, pp. 90-98, 2014.

[2] A. S. Putra, "Paperplain: Execution Fundamental Create Application With Borland Delphi 7.0 University Of Mitra Indonesia," 2018.

[3] A. S. Putra, "2018 Artikel Struktur Data, Audit Dan Jaringan Komputer,' 2018.

[4] A. S. Putra, "ALIAS MANAGER USED IN DATABASE DESKTOP STUDI CASE DB DEMOS."

[5] A. S. Putra, "COMPREHENSIVE SET OF PROFESSIONAL FOR DISTRIBUTE COMPUTING."

[6] A. S. Putra, "DATA ORIENTED RECOGNITION IN BORLAND DELPHI 7.0."

[7] A. S. Putra, "EMBARCADERO DELPHI XE 2 IN GPU-POWERED FIREMONKEY APPLICATION."

[8] A. S. Putra, "HAK ATAS KEKAYAAN INTELEKTUAL DALAM DUNIA TEKNOLOGY BERBASIS REVOLUSI INDUSTRI 4.0."

[9] A. S. Putra, "IMPLEMENTASI PERATURAN PERUNDANGAN UU. NO 31 TAHUN 2000 TENTANG DESAIN INDUSTRI BERBASIS INFORMATION TECHNOLOGY."

[10] A. S. Putra, "IMPLEMENTATION OF PARADOX DBASE."

[11] A. S. Putra, "IMPLEMENTATION
OF TRADE SECRET CASE STUDY SAMSUNG MOBILE PHONE."

[12] A. S. Putra, "IMPLEMENTATION PATENT FOR APPLICATION WEB BASED CASE STUDI WWW. PUBLIKLAMPUNG. COM."

[13] A. S. Putra, "IMPLEMENTATION SYSTEM FIRST TO INVENT IN DIGITALLY INDUSTRY."

[14] A. S. Putra, "MANUAL REPORT \& INTEGRATED DEVELOPMENT ENVIRONMENT BORLAND DELPHI 7.0."

[15] A. S. Putra, "PATENT AS RELEVAN SUPPORT RESEARCH."

[16] A. S. Putra, "PATENT FOR RESEARCH STUDY CASE OF APPLE. Inc."

[17] A. S. Putra, "PATENT PROTECTION FOR APPLICATION INVENT."

[18] A. S. Putra, "QUICK REPORT IN PROPERTY PROGRAMMING."

[19] A. S. Putra, "REVIEW CIRCUIT LAYOUT COMPONENT REQUIREMENT ON ASUS NOTEBOOK."

[20] A. S. Putra, "REVIEW TRADEMARK PATENT FOR INDUSTRIAL TECHNOLOGY BASED 4.0."

[21] A. S. Putra, "TOOLBAR COMPONENT PALLETTE IN OBJECT ORIENTED PROGRAMMING."

[22] A. S. Putra, "WORKING DIRECTORY SET FOR PARADOX 7."

[23] A. S. Putra, "ZQUERY CONNECTION IMPLEMENTED PROGRAMMING STUDI CASE 


\section{PT.BANK BCA Tbk."}

[24] A. S. Putra, D. R. Aryanti, and I. Hartati, "Metode SAW (Simple Additive Weighting)

sebagai Sistem Pendukung Keputusan Guru Berprestasi (Studi Kasus: SMK Global Surya)," in Prosiding Seminar Nasional Darmajaya, 2018, vol. 1, no. 1, pp. 85-97.

[25] A. S. Putra and O. M. Febriani, "Knowledge Management Online Application in PDAM Lampung Province," in Prosiding International conference on Information Technology and Business (ICITB), 2018, pp. 181-187.

[26] A. S. Putra, O. M. Febriani, and B. Bachry, "Implementasi Genetic Fuzzy System Untuk Mengidentifikasi Hasil Curian Kendaraan Bermotor Di Polda Lampung," SIMADA (Jurnal Sist. Inf. dan Manaj. Basis Data), vol. 1, no. 1, pp. 21-30, 2018.

[27] A. S. Putra, H. Sukri, and K. Zuhri, "Sistem Monitoring Realtime Jaringan Irigasi Desa (JIDES) Dengan Konsep Jaringan Sensor Nirkabel," IJEIS (Indonesian J. Electron. Instrum. Syst., vol. 8, no. 2, pp. 221232.

[28] D. P. Sari, O. M. Febriani, and A. S. Putra, "Perancangan Sistem Informasi SDM Berprestasi pada SD Global Surya," in Prosiding Seminar Nasional Darmajaya, 2018, vol. 1, no. 1, pp. 289-294. 